\title{
APPLICABLE POSSIBILITY STUDIES ON A HUMANOID ROBOT TO COOPERATIVE WORK ON CONSTRUCTION SITE WITH A HUMAN WORKER
}

\author{
Junichiro MAEDA: Deputy Director, Institute of Technology, SHIMIZU Corporation, Dr.Eng. \\ Address: 4-17, Etchujima 3-chome, Koto-ku, Tokyo 135-8530, JAPAN \\ Mail address: jmaeda@shimz.co.jp \\ Hiroo TAKADA: Visiting Researcher, Advanced Research Institute for Science and \\ Engineering, WASEDA University, Dr. Eng. \\ Address: 4-1, Okubo 3-chome, Shinjuku-ku, Tokyo 169-8555, JAPAN \\ Mail address: takada-01@kurenai.waseda.jp \\ Yoshio ABE: Manager, Machinery Department, Building Headquarters. SHIMIZU Corp. \\ Address: 2-3, shibaura 1-chome, Minato-ku, Tokyo 105-8007, JAPAN \\ Mail address: y_abe@shimz.co.jp
}

\begin{abstract}
Humanoid robot walks by a pair of legs and works using two hands. About this humanoid robot, authors investigate about the possibility of its application to various works on site.

Investigation is conducted by the following three methods. The first one is an investigation of matching the demand function of the latest work on the construction site with the performance which a humanoid robot holds. The second is an investigation of the way that a worker cooperates with the most advance humanoid robot. In an experiment, they transport a lightweight board from a place to a final work place and attach it together. The name of the humanoid robot used for the experiment is HRP-2, developed by the METI national project. The human worker is a fixtures carpenter. And the third is an analysis of the needs of managers of construction site on the humanoid robot.

The results of the investigation show that a humanoid robot can be applied to the on-site continuation works of 24 hours, works with high stress and degree of fatigue, various impersonal works, works in which sensors are utilized, and the business in a construction site office.
\end{abstract}

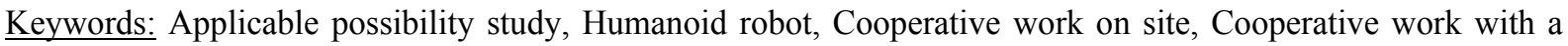
human worker

\section{INTRODUCTION}

Change of the Japanese population composition for 50 years at the first half of the $21^{\text {st }}$ century deserves attention. The production age or the golden age from 15 to 65 years old decreases by about 33 million people, and 65 or more years old increases by about 9 million people. The reduction in the golden age brings a big change to society and economy. This means that the construction industry will be also influenced greatly. The construction industry must draw up the solution of this subject immediately. In this paper, results of the investigation about the possibility of introduction of humanoid robot to construction site is discussed.

\subsection{The present condition and the problem of the construction industry}

The labor productivity of the construction industry of Japan has hung low remarkably compared with other industries or the European and American construction industry. Before, time with labor productivity higher than a manufacturing industry also had the construction industry. However, it centered on the manufacturing industry as introduction of automation technology got into stride with the production line of a manufacturing industry, and also the predominancy of the industry was established.

Although the number of workers of construction industry became $6,850,000$ people of a peak 1997 , they are leveling off or a decrease of fine after it. In the present condition, there is no feeling of a labor shortage like at the time of a bubble term. However, since the younger age group likes the short working hours, and has a tendency to avoid $3 \mathrm{~K}$ (Dangerous, Dirty, Harsh) so-called work, there is a possibility that near future construction laborers, especially skilled workers may run short. Moreover, a skilled worker's average age are going up steadily and the measure to the laborers of an advanced age is needed to be formed.

From 1961 to today, the industrial accident of the construction industry is continuing the worst accident occurrence number of cases, and occupies 40 to $50 \%$ 
of all industries. Although the number of the deceased in the construction industry was less than $40 \%$ of all industries in 1998 , this is also because the amount of construction became less by the economic slump, and the work safety of a construction site is hard to be referred to as having been improved certainly.

\subsection{Expectation for the possibility of humanoid robot}

Development of the robot for construction has tackled positively from the 1980's that the problem of such the construction industry should be solved. However, most of the conventional construction robot were realized as "an exclusive automatic machine", and it was foundations to take out a scale merit, by managing many finite repetition work. On the other hand, the correspondence to unfixed type work and complicated work and movement of the irregular ground are possible for a humanoid robot. Moreover, since a humanoid robot has affinity with human, it can share the work on condition of man and it is suitable for working in harmony with man. Because of it, it is expected to robotization of construction work as what opens the new possibility.

\section{METHOD OF INVESTIGATION}

Humanoid robot walks by a pair of legs and works using two hands. Authors investigated and examined that what work is suitable for this humanoid robot working in cooperation with man on a construction site, and that what performance and capability of robot were needed again in that case. Below, the concrete investigation method is described.

\subsection{The enforcement items of investigation}

Investigation was conducted in the following methods and procedures. First, investigation of matching the function of the work of the construction site with the performance of a humanoid robot was conducted. It referred to the level demanded by the work of a construction site for every robot's performance and capability, and the future subject was clarified. Next, one construction work was made to do experimentally using the humanoid robot which is advancing most in the present condition, and the subject required for utilization was extracted. Furthermore, the needs of construction site were analyzed, the conditions of the work which heightens the introductory effect of humanoid robot were clarified, and the concrete example of application was shown.

\subsection{Humanoid robot which was investigated}

The humanoid robot made into the object of investigation this time is a robot with which it is referred to as HRP-2 and development is progressing most in Japan now. Research and development in this robot was done in "Humanoid Robotics Project" of the Ministry of Economy, Trade and Industry undertaken from 1998 to 2002. Figure 1 shows the appearance of HRP-2 and an example of its application, and Table 1 shows the main performance specification. HRP-2 can walk along the irregular ground. Moreover, while the man itself who does cooperation work worked, it became possible to manage a robot. For the purpose, a new robot's hardware, advanced 2-pair-of-shoes walk technology, the communication technology of man and a robot, environmental recognition technology, the cooperation control technology of arm and leg, etc. were developed.

\section{INVESTIGATION BY FUNCTIONAL ANALISYS METHOD}

In this investigation, the performance and capability which are needed for the humanoid robot which does construction work first were developed over several order. Next, the function of the work being done in the usual construction site was similarly developed over several order. Furthermore, this robot's performance and capability, and the function of construction work were made to contrast, and the matrix was created. Based on this matrix, the level demanded in the construction spot was compared with the present level for every a robot's performance and capability, and future research subject and target were clarified.

\subsection{Functional deployment of performance of humanoid robot}

The result which carried out functional deployment of the performance and the capability needed for a humanoid robot is shown in Table 2. As primary deployment, seven items of "move capability", "work capability", "intention transfer capability", "reliability", "knowledge power", "recognition capability", and "judgment capability" were chosen. Secondary deployment is items of the individual performance or capability included in the item of primary deployment. The 3rd deployment has specified the contents of each item technically further. Usually, the object which specifies a performance and capability when designing a robot is the level of this 3rd deployment. This functional deployment was performed on condition that the following.

[1] It considered as the object of deployment of performance and capability of a robot required to do actual work, such as autonomy, athletic ability, etc.

[2] The performance required to do outdoor work, such as irregular ground movement, was also made into the object of deployment.

[3] It considered as the object of deployment of capability required to do cooperation work, such as intention transfer capability. 


\subsection{Functional deployment of construction works}

The work function currently carried out in the general construction site was developed. As primary deployment, nine items of "a preliminary survey", "temporary work", "digging and the foundation", "underground structure", "ground structure", "waterproofing", "finish construction", "equipment construction", and "exterior and inspection" were taken up. Furthermore, deployment to the 4th order was performed about each function. A part of result developed to the 4 th order is shown in Table 3 . This functional deployment was performed on condition that the following.

[1] Planning, implementation and inspection of construction work were set as the object of deployment. However, the row of the developed function is not in agreement in order of actual work.

[2] Functional deployment was performed based on so-called 4M. Construction plan, drawings, manuals, etc. are mentioned as Method. As Man, they are supervision persons, administrators, workers, etc. As Machine, they are construction machines, temporary materials, tools, inspection apparatus, etc. Moreover, many building materials are mentioned as Material.

[3] The function about the safety and the environmental problem of work was also considered subordinately.

\subsection{The degree analysis of relation of a robot's function and construction work}

Based on deployment of construction work and a robot performance, the degree of relation of construction work and a robot performance was examined. In order to examine this degree of relation, the functional contrast matrix described below was created. The vertical axis of the matrix is the developed construction work function. (The 4th deployment of Table 3, 262 items) The horizontal axis is developed about a robot's performance and capability. (Secondary deployment of Table 2, 26 items) Each cell of the matrix evaluates the strength of both degree of relation. Evaluation of the strength of the degree of relation was evaluated in seven stages (0-6) for every cell. Average value and the standard score were calculated about construction work function, and each performance and capability of a robot using this figure. Especially the strong thing of relation with construction work function was the following 13 items in a robot's performance and capability as a result of this analysis. They were an "irregular standpoint line", "course generation", "transportable weight", "hand flexibility", "positioning accuracy", "conversation capability", "communication capability", "fall stability", "on-site data", "material knowledge", "memory", "image recognition", and "various sensing". About these 13 items, the subjects and target of research and development which should be done from now on were clarified by grasping the difference of the required performance level and the achievement level of HRP-2. Table 4 shows the examined result about "Conveyance weight" as an example.

\section{APPLICABILITY INVESTIGATION BY WORK EXPERIMENT}

The construction work supposing HRP-2 developed this time was work which carries a lightweight wall panel in harmony with man, and is built in a building. The human worker is a fixtures carpenter. Based on the result of a construction experiment, the application possibility to the actual site was investigated about this selected work.

\subsection{The contents of work set as the object of investigation}

The flow of the work used as the candidate for investigation is as follows. First, the robot detects the dump of wall panels by the image recognition of installed camera, and walks to near it. Then, after detecting again the position which holds a panel by image recognition correctly, the panel is lifted in harmony with a human worker. And a panel is carried in harmony with him, receiving directions by voice and power feeling of a human worker. If a building is approached, the robot will build a panel in the building in response to voice directions of the human worker. Photograph 1 shows signs that the position where the robot holds the panel is detected. Photograph 2 shows the situation of carrying the panel in harmony with man. Moreover, photograph 3 shows signs that a panel is built.

\subsection{Evaluation of the application possibility in the supposed work}

The contents, and its conditions and required capability of the work being done in the general construction site were investigated about conveyance and assembly work of wall panels. On the other hand, the contents of the work supposed by HRP-2, and the results of the experiment was summarized in Table 5. Furthermore, comparison contrast of both was performed, performance and capability of the robot which runs short of realizing conveyance and assembly work of the wall panel in the actual construction site were summarized. Table 6 shows future research subjects and target.

\section{INVESTIGATION OF THE APPLICA- TION POSSIBILITY SEEN FROM THE POSITION OF CONSTRUCTION SITE}

Before introducing a humanoid robot into the construction site, what should be kept in its needs and mind by the side of the site was examined. 
And based on it, the conditions on which humanoid robot demonstrates an introductory effect on the site were probed, and the concrete works and business in the site suitable for the condition were selected as an example of application.

\subsection{Change of the construction site expected by the introduction of humanoid robot}

Concerning to the subject of the construction industry stated in Chapter 1, the shift from the production system of the conventional human subject to the system of the machine subject is required. In the site where it was mechanized and the robots were introduced, the following change is expectable.

[1] A suitable work assignment of man and robot is performed, the work method and procedure are simplified and settlement of component is also simplified so that it may be easy to robotize work.

[2] The unit of work management will turn into an hour unit from the present day unit. Materials are just carried in to an in time and real time production control system also comes to be performed.

[3] The amount of carrying in and the amount of assembly work of materials increase. Therefore, the role of the site plant prepared in site becomes important. By this site plant, the construction site can be worked like a manufacture factory and operation also becomes possible for 24 hours.

[4] The measure for calamity prevention on a construction site accelerates. By a robot's introduction, a possibility that perfect safety of the site which was years of wish of the construction industry will be realized increases.

[5] If a humanoid robot is introduced, curtailment of the worker station and smoking place, toilets, diningrooms etc. which were required only for human workers is attained, and can reduce construction expense.

\subsection{Works of high application possibility of humanoid robot}

In consideration of the feature of a humanoid robot, and technical implementability, work and business equipped with the following conditions were selected as a candidate for application from construction work functions. According to progress of future technical development, first, as the first step, the theme of [1], [2], and [3] should be tackled, and the subject of [4], [5], and [6] which is the ultimate purpose should be challenged in the next step.

[1] Work and business which do not require advanced functions, such as an irregular standpoint line and complicated handling

(ex.) Entrance and leaving management of workers, the surveillance in the site, survey, operation of the elevator for construction, etc.

[2] Work and business which can fully employ efficiently various kinds of sensor ability which the robot equipped

(ex.) Check of the equipment for work safety, or the equipment for security, construction inspection, quality check, etc.

[3] Work and business which can employ efficiently the capability that a lot of information is far held compared with a human worker, and the information on external can be taken in on real time

(ex.) An on-site administrator and a design supervision person are provided with information, such as a plan document and the construction point, on real time.

[4] Work and business which man does not want to do personally even if some are inferior to a human worker in respect of capability.

(ex.) Cleaning of the health facilities in the site, cleaning of floor or glass

[5] Work and business which must do prolonged simple repetition work, without feeling stress and fatigue

(ex.) Night work of the public works in a city., conveyance and repetition work of an assembly, the crime prevention patrol around on-site

[6] Work and business as which continuation work is required like operation for 24 hours

(ex.) Concrete placing of silo construction etc., rush work at the time of construction delay

\section{FURTHER RESEARCH SUBJECTS}

In order to adopt a humanoid robot as the work or business of an actual construction site, we have to solve many technical subjects. We have to tackle research and development of the hand's dexterity, work speed, and the stable walk on an irregular ground, cooperation control with man or a robot, improvement in reliability or durability, etc. Furthermore, the examination of the design proposal of a construction production system on condition of introduction of humanoid robot, and the improvement in a robot's cost performance will also become future big research subjects.

\section{Acknowledgments}

This research is done as sponsored research of New Energy and Industrial Technology Development Organization (NEDO) of Japan. I want to describe gratitude anew here.

\section{REFERENCES}

[1] K. Yokoyama, J. Maeda, others, "Application of Humanoid Robots for Cooperative Tasks in the Outdoors", Proc. Int. Conference on Intelligent Robots and Systems" Workshop2, 2001

[2] Development and the future of a humanoid robot, The society magazine of Robotics Society of Japan, Vol.20, No.7, 2002 


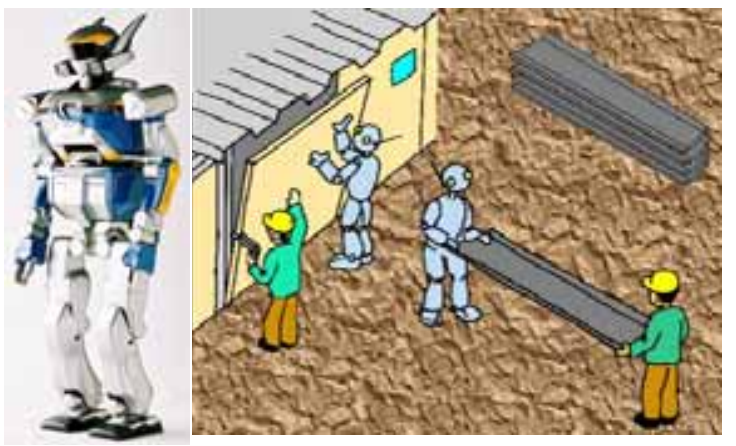

Figure 1. HRP-2 and an Example of its Application

Table 1. Main Performance Specification of the HRP-2

\begin{tabular}{|c|c|c|}
\hline \multirow{4}{*}{ Dimensions } & Height & $1,539 \mathrm{~mm}$ \\
\cline { 2 - 3 } & Width & $621 \mathrm{~mm}$ \\
\cline { 2 - 3 } & Depth & $355 \mathrm{~mm}$ \\
\hline Weight (including Battery) & $58 \mathrm{~kg}$ \\
\hline \multirow{4}{*}{ Degree of Freedom } & 30 D.O.F \\
\cline { 2 - 3 } & Neck & 2 D.O.F \\
\cline { 2 - 3 } & Waist & 2 D.O.F \\
\cline { 2 - 3 } & Arms & $6 \times 2$ D.O.F \\
\cline { 2 - 3 } & Hands & $1 \times 2$ D.O.F \\
\cline { 2 - 3 } & Legs & $6 \times 2$ D.O.F \\
\hline \multicolumn{2}{|c|}{ Speed } & Max.2.0km $/ \mathrm{h}$ \\
\hline \multicolumn{2}{|c|}{ Hand Grip Force } & $2 \mathrm{~kg} /$ each arm \\
\hline \multicolumn{2}{|c|}{ Conveyance Weight } & $6 \mathrm{~kg} /$ both arm \\
\hline
\end{tabular}

Table 2. Functional Deployment of the Robot's Performance and Capability

\begin{tabular}{|c|c|}
\hline Primary Deployment & Secondary Deployment \\
\hline \multirow{4}{*}{ Move Capability } & Irregular ground movement \\
\hline & Move speed \\
\hline & Move course generation \\
\hline & Conversion of direction \\
\hline \multirow{7}{*}{ Work Capability } & Conveyance weight \\
\hline & Speed of operation \\
\hline & Movable range \\
\hline & Flexibility of a hand \\
\hline & Positioning accuracy \\
\hline & Continuation operation time \\
\hline & Working hours \\
\hline \multirow{2}{*}{ Intention transfer capability } & Conversation capability \\
\hline & Communication capability \\
\hline \multirow{4}{*}{ Reliability } & Stability over falling \\
\hline & Protection nature to falling \\
\hline & Danger of reckless move \\
\hline & Frequency of failure \\
\hline \multirow{4}{*}{ Knowledge power } & Construction site data \\
\hline & Knowledge of materials \\
\hline & Memory capability \\
\hline & Knowledge of regulations \\
\hline \multirow{2}{*}{ Recognition capability } & Image recognition \\
\hline & Detection of states \\
\hline \multirow{3}{*}{ Judgment capability } & Circumstantial judgment \\
\hline & Change of procedure \\
\hline & Common sense \\
\hline
\end{tabular}

Table 4. Results of the Analysis about "Conveyance Weight" (as an example)

\begin{tabular}{|c|}
\hline Primary Deployment: Work Capability \\
\hline Secondary Deployment: Conveyance Weight \\
\hline
\end{tabular}

Required performance level in actual site

\begin{tabular}{|l|l|l|}
\hline \multicolumn{1}{|c|}{ Kind of work } & Performance Level & \multicolumn{1}{c|}{ Frequency } \\
\hline Mold assembly & 5 to $10 \mathrm{~kg}$ & much \\
\hline Iron bar assembly & 2 to $20 \mathrm{~kg}$ & very much \\
\hline Concrete placing & 5 to $10 \mathrm{~kg}$ & very low \\
\hline Lifting up work & 5 to $8 \mathrm{~kg}$ & very low \\
\hline Interior finish work & 10 to $20 \mathrm{~kg}$ & very much \\
\hline Equipment work & 5 to $30 \mathrm{~kg}$ & much \\
\hline
\end{tabular}

Achieved performance level of HRP-2

\begin{tabular}{|l|l|}
\hline Hand grip force & $2 \mathrm{~kg} /$ each arm \\
\hline Conveyance weight & $6 \mathrm{~kg} /$ both arm \\
\hline
\end{tabular}

Subject and target of future research and development

\begin{tabular}{|l|l|}
\hline STEP1 \\
\hline Required period & 5 years \\
\hline Target of performace & Conveyance weight 15kg \\
\hline Realizable works & Interior finishing panels, Equipments \\
\hline Conditions for realizing & $\begin{array}{l}\text { Frexibility of hands, Acquisition of work } \\
\text { know-how, Rise and fall of scaffold, etc. }\end{array}$ \\
\hline
\end{tabular}

\begin{tabular}{|l|l|}
\hline STEP1 \\
\hline Required period & 10 years \\
\hline Target of performace & Conveyance weight 30kg \\
\hline Realizable works & Iron bars, Wooden and metal fittings \\
\hline Conditions for realizing & $\begin{array}{l}\text { Improvement in capability of handling, } \\
\text { knowledge and movement, etc. }\end{array}$ \\
\hline
\end{tabular}

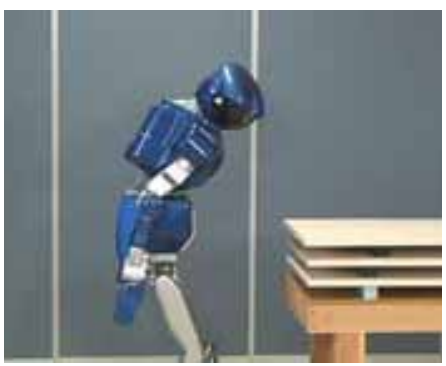

Photograph 1. Detection of the Holding Position

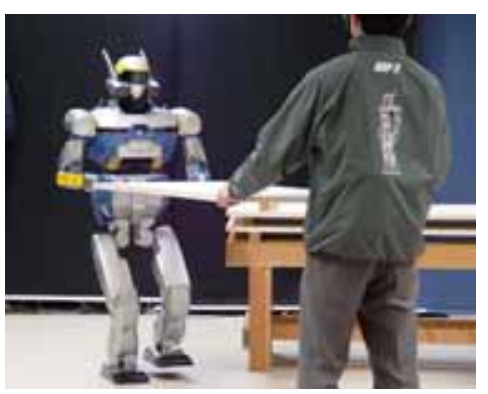

Photograph 2. Situation of Carrying a panel

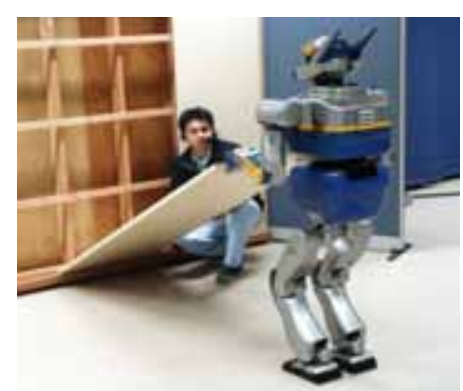

Photograph 3. Signs of a Panel Building 
Table 3. Functional Deployment of the Construction Work

\begin{tabular}{|c|c|c|c|}
\hline 1st Deployment & 2nd Deployment & 3rd Deployment & 4th Deployment \\
\hline \multirow[t]{19}{*}{ Finish construction } & \multirow[t]{6}{*}{ Display of attachment position } & \multirow{3}{*}{$\begin{array}{l}\text { Grasp of the attachment position } \\
\text { information }\end{array}$} & Grasp of the position and size of ground material \\
\hline & & & Grasp of the position and size of finish material \\
\hline & & & Grasp of the position and size of openings \\
\hline & & \multirow{3}{*}{$\begin{array}{l}\text { Display of the attachment position } \\
\text { of component }\end{array}$} & Check of the datum lines \\
\hline & & & Display to the floor of the attachment position \\
\hline & & & Inspection of the position displayed \\
\hline & \multirow{2}{*}{$\begin{array}{l}\text { Guidance of the carried-in } \\
\text { component }\end{array}$} & \multirow[t]{2}{*}{ Check and directions of a track } & The check of the body number of a track \\
\hline & & & Directions of the waiting circle place of a track \\
\hline & \multirow{5}{*}{$\begin{array}{l}\text { Inspection of the carried-in } \\
\text { component }\end{array}$} & \multirow{2}{*}{$\begin{array}{l}\text { Check of the ID-number of carried-in } \\
\text { component }\end{array}$} & Check of the kind and quantity of component \\
\hline & & & \\
\hline & & \multirow{3}{*}{$\begin{array}{l}\text { Check of the contractor who uses the } \\
\text { component }\end{array}$} & Check of carrying-in schedule of the contractor \\
\hline & & & Connection to the receipt contractor \\
\hline & & & Delivery of the components to the contractor \\
\hline & \multirow{2}{*}{$\begin{array}{l}\text { Stock of the carried in } \\
\text { component }\end{array}$} & \multirow{2}{*}{$\begin{array}{l}\text { Check of the place and stock work } \\
\text { execution }\end{array}$} & Collation of the stock yard to the component \\
\hline & & & Stock to the specified yard of the component \\
\hline & \multirow{4}{*}{$\begin{array}{l}\text { Transport to the conveyance } \\
\text { place }\end{array}$} & \multirow{2}{*}{$\begin{array}{l}\text { Check of the kind and quantity of the } \\
\text { stocked component }\end{array}$} & Check of the kind of stocked component \\
\hline & & & Check of the quantity of the stocked component \\
\hline & & \multirow[t]{2}{*}{ Transport of the selected component } & Putting on a truck of the components \\
\hline & & & Transport of the truck to the conveyance place \\
\hline
\end{tabular}

Table 5. Results of the Construction Experiment by applying the HRP-2

\begin{tabular}{|l|l|l|}
\hline \multicolumn{1}{|c|}{ Work element } & \multicolumn{1}{|c|}{ Contents of the experiment } & \multicolumn{1}{c|}{ Attained performance } \\
\hline \multirow{3}{*}{ Check of panel dump } & Direction with human voice & Understanding of the registered conversation sentence \\
\cline { 2 - 3 } & Search of a panel position with camera & Recognition of 2 or 3m away panels by image processing \\
\hline \multirow{3}{*}{ Walk on calculated course } & Course calculation to panel dump & Calculation of the course to a panel dump \\
\cline { 2 - 3 } & Walk movement & Walk movement along the calculated course \\
\cline { 2 - 3 } & Walk of the irregular ground above floor & Walk of the level difference of 40mm, and 5\% of inclination ground \\
\hline \multirow{3}{*}{ Check of grasping position } & irection with human voice & Understanding of the registered conversation sentence \\
\cline { 2 - 3 } & Search of a panel position with camera & Recognition of panel edge by image processing \\
\cline { 2 - 3 } & Compensation of the standing position & It walks and rectifies in the position suitable for holding a panel. \\
\hline Grasp and lift of a panel & Direction with human voice & Understanding of the registered conversation sentence \\
\hline & Positioning the hand and grasping panel & Holding of a panel by closing the 1 flexibility hand \\
\hline & Lifting a panel & Lifting of a panel of weight which can be conveyed \\
\hline Conveyance of a panel & Direction with human voice & Understanding of the registered conversation sentence \\
\hline & Guiding a panel in arbitrary directions & Power and torque felt by the wrist determine a direction. \\
\hline Build lump of a panel & Direction with human voice & Understanding of the registered conversation sentence \\
\hline & Stop of holding a panel & Opening the 1 flexibility hand \\
\hline & Raising and building a panel & Walking forward pushing a panel \\
\hline
\end{tabular}

Table 6. Future Research Subjects and Target

\begin{tabular}{|l|l|l|}
\hline \multicolumn{1}{|c|}{ Performance } & \multicolumn{1}{|c|}{ Research subject } & \multicolumn{1}{c|}{ Development target } \\
\hline Irregular ground movement & Enlargement of height difference and inclination & 10cm of height difference and 10\% of inclination \\
\hline Move course generation & Function to avoid obstacle & Detection and avoidance of opening and obstacle \\
\hline Conveyance weight & Increase of conveyance weight & Conveyance of 15kg weight by both hands \\
\hline Flexibility of a hand & Grasping of tools and cylindrical materials & Flexibility of opening/closing and gripping \\
\hline Conversation capability & Increase the registered conversation sentence & Registration of sentence of lots of common operations \\
\hline Communication capability & Acquisition of information from evnironment & Data acquisition utilized RFID and data-base \\
\hline Image recognition & Increase of the candidate for detection & Object recognition of 100-piece order \\
\hline Detection of states & Contents reading of state display equipment & Reading of bar code or scale of display equipment \\
\hline
\end{tabular}

